\title{
Research on College English Teaching Model Optimization under Information Technology Background: Taking Xi'an University as Empirical Analysis Example
}

\author{
Wei Qing \\ Xi'an University, \\ Xi'an, Shaanxi,710065 China
}

\begin{abstract}
In this paper, we conduct research on college English teaching model optimization under information technology background with the Xi'an university as the empirical analysis example. The professional talent training is a systems engineering, to cultivate excellent talents with international communication and competition ability can't just rely on their own teaching quality improvement of the academic disciplines, such as no college English in helping to train the students in English for the professional study and research of academic ability, students can't understand the foreign teachers' English teaching or lecture, can't direct reading professional literature in English, it is hard to reach this goal. Under this condition, we enhance the teaching approaches with integration of information technology and conduct empirical analysis on Xi'an university.
\end{abstract}

Keywords- English Teaching, Information Technology, Xi'an University, Empirical Analysis.

\section{Introduction}

The function of education is to convert the social and cultural structure of macro micro for student individual psychological structure, the transformation must through the students' internalization to be effective. Therefore, the education must be on the premise of the subjectivity of the students, so as to promote the development of the individual and with the popularity of the multimedia technology and computer network application, as psychologists the deepening of the research on human cognitive law learning process, as the modern education technology latest theoretical foundation of constructivism is quickly popular in the contemporary world [1-3].

In institutions of higher learning in the process of teaching, the teaching of college English teaching occupies the time, the input of faculty, students energy cost are more, but because many institutions of higher learning are not clear the purpose of the college English teaching, teaching for teaching, or the teaching for the CET exams, rarely consider the improvement of teaching is aimed at students' quality, both in daily teaching process to separate, not only the teaching efficiency is poor as college students' English level is slow, but also for the general cultivation of the college students' humanistic quality and improve did not play a proper role. According to the literature survey, the constructivism for the English teaching could be summarized as the follows. (1) Knowledge is not passively accept, but by individuals with cognitive ability actively constructing. Knowledge can't be in the form of entity exists outside the individual with the real understanding of knowledge can be only by the learners themselves based on their background and the experience in construction, depending on the specific situation of the learning process. (2) Emphasizes the significance of learners to build their knowledge is not to say that the learners a person study in isolation, learners from the opportunity of presenting their views, contradicting benefit, and through such a basic process to reconstruct their own views. (3) Based on new media and traditional media based on the classroom computer complement each other, the mutual cooperation, complement each other. This new composite media is no longer help 
teachers teach knowledge means and methods, but to create scenarios to help learning and conversation.

Use of multimedia teaching can make students oriented picture lively, colorful, affectionately. This has changed the past students in the class can only look at the blackboard, and listen to the teacher speak of monotonous mode. Multimedia technology can provide rich and colorful variety of general information such as the sound, light, electricity, etc., to make the classroom become colorful, greatly optimize teaching atmosphere and make information communication between teachers and students system becomes rich and vivid, such a harmonious teaching situation, greatly increase interest in the general learning activities. Under these circumstances, we conduct research on the college English teaching model optimization under information technology background with the Xi'an university as the empirical analysis example in this paper [4].
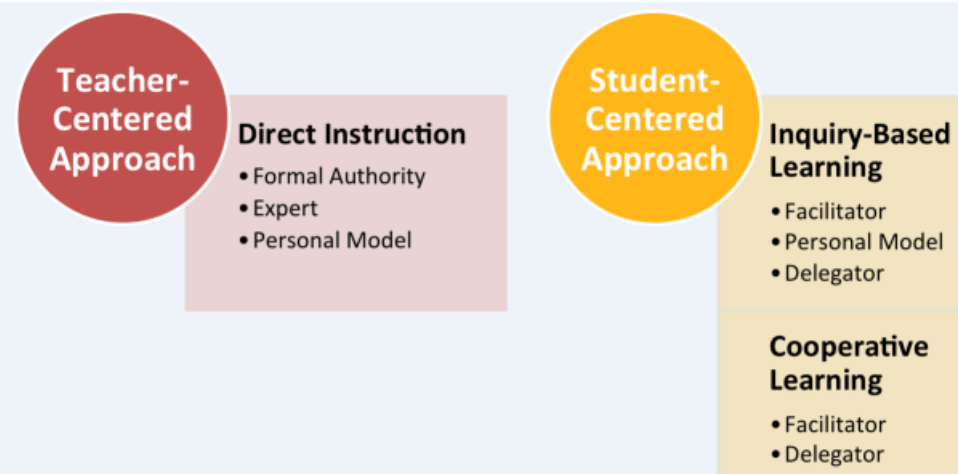

Figure 1. The Common College English Teaching Model

\section{The Proposed Perspective and Methodology}

The Introduction of Xi'an University. Specialty construction is an important infrastructure in the teaching of undergraduate course of colleges and universities, is the key link to improve the quality of the undergraduate course personnel training and the core of the basic construction of other items. A quantity and quality of construction of key professional school is the school running characteristics and level, teaching and scientific research level of important symbol.

According to the review and survey, we summarize the characteristics of the Xi'an university as follows. (1) For the purpose of education, improve the teaching quality of education in an all-round way as the school always adheres to the party's education policy, in order to cultivate applied talents with the innovative spirit and practical ability as the goal, emphasizes the all-round development of students' physique and improve the comprehensive quality of the college students. (2) Adhere to the direction and create flexible mechanisms, with the advantages of flexible organizational mechanism, it is suitable for the characteristics of young students, easy to arouse the enthusiasm of the students to participate in various interest activities of the organization and conduct is consistent with the social mainstream culture, students grow up that has a clear orientation of target. (3) Take the student as the center, while set up the youth stage. The second classroom activities to the students' interests as the guidance to make the most of the students can find themselves to participate in the activities of the project, greatly stimulated the enthusiasm of students to participate in activities, reflecting the driving force of the second classroom activity, really exert the principal role of students and strengthen the student's main body status to 
promote the unity of the students take the initiative to drive [5].

The Information Technology Aided Teaching Mode. With the rapid development of society and era, information technology gradually permeated all areas, including the cause of education. Timely and appropriately auxiliary teaching application of the information technology, not only can provide mathematics teaching with a new learning environment, rich class culture also help students learning initiative and enthusiasm into full play.

Information technology and curriculum integration will need to redesign the existing curriculum and teaching material as teachers need to change the pattern of teaching and learning. But information technology and curriculum integration of information technology hardware equipment, information skills of the teachers and the teaching design ability, the students the limitation of basic information processing capabilities, and many of the other factors, so the information technology and curriculum integration has a lot of difficulties in the implementation and computer aided teaching only requires teachers to use existing software, to the teacher's curriculum and teaching design ability request is not high, so the computer aided teaching much easier to implement. Referring to the literature survey and general review, we summarize the applications of IT as the follows [6].

- With the help of information technology can provide students with imagination of materials, set up a bridge of representation and thinking, speed up into the language situation, make the students understanding of English language content layer upon layer, step by step to deepen to emotional experience, students explore in the appeal and shared language art in entertainment.

- Material information, the teaching material content to keep pace with The Times. With the aid of network learning, in the repository, in view of the textbook content and research, expanding preview can break lay particular stress on the idea of language art and ignore the social and the cultural standard, causes the student to feel the spirit of the age and freshness.

- Auxiliary English teaching using basic information technology can create the lively teaching atmosphere, make the abstract, difficult to understand, hard to memory language knowledge into specific and visual image and the image of symbol, thus make students willing to learn.

For the question of how multimedia computer assisted instruction and all kinds of the different opinions. Face different point of the view, we should put our heads together, for a suitable way to the schools of the actual situation. Education of ecological environment are often the mutual penetration of natural factors and social factors, material factors and mental factors mutual accommodation of compound ecological environment, which means it is a including general natural environment, social environment and normative environment of the compound ecological environment. According to the education ecology point of view, education subject and education between ecological environments are interdependent and influence each other, they constitute education ecological system [7].

Efforts to establish and improve the evaluation system of multimedia computer assisted instruction as the evaluation to the development of the software in an objective and the fair. Of the multimedia computer assisted instruction this new modern teaching means, in the current teaching role to correctly estimate that is reflected from the figure two. 
Integrated Information Improvement ${ }^{\mathrm{TM}}$ Model

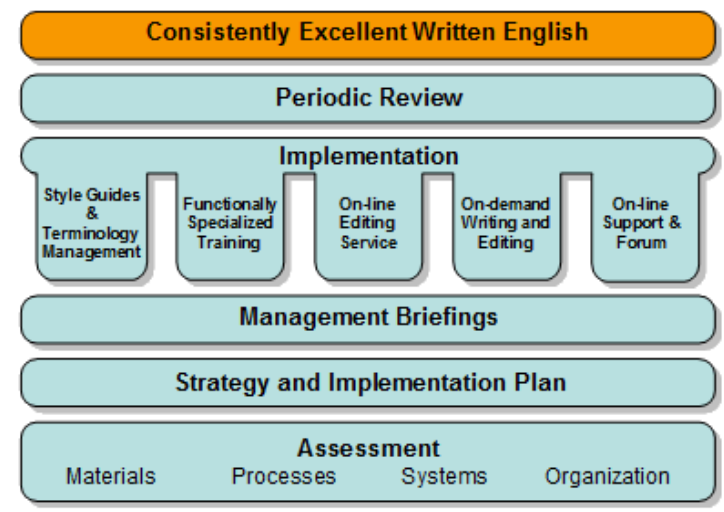

Figure 2. The Principles of the Information

Technology Assisted Education Architecture

The Teaching Model Optimization. The teaching process optimization theory is the former Soviet Union educator and class. Its meaning is: according to the training objectives and the specific teaching task, considering the actual students, teachers and the teaching conditions, design the best teaching plan according to the teaching rule, the minimum resources consumption benefits the highest results. The results reflected in the students is class everyone can get the most reasonable education and development. The core of this theory is to integrated solutions to education and general task in the development of personality, including the development of creative talents and the key is to deal with time, effort, cost and effect of education, the relationship between yields is lower consumption.

Teaching history shows that the teaching optimization have not blind, it guided by some thought, have their own clear goals while this goal is the study of teaching main body, the human activities regularly. Ever since ancient times, humans about the optimization of the teaching experience, from objective nature to human nature from the mechanical view towards the system view, from instinct theory to emotional theory, from the external interaction to internal motivation to arouse the change of the course. Applications of the teaching process optimization theory can be generally organized as the following aspects. (1) As educators to impart information, to the general point of view of educatees, perception, grasp the emphases and difficulties of teaching, and then study the best method of the teaching, make the educatees in spending at least under the condition of time and energy, to master the key to overcome the difficulties. (2) By educators in the processing, refining the teaching information, optimize the teaching information, selectively add, delete the teaching content, make the educatees in spending at least under the condition of time and energy, cognitive, accept the essence of knowledge information, and get the best results. (3) From the numerous and complicated teaching forms and methods to optimize the suitable for the specific conditions of the teaching form and teaching method, to make every educator is lack of knowledge to knowledge, confused in to clear. Make every educatee has the opportunity to show talent to accept incentive [8].

The Enhanced English Teaching Paradigm. College English teaching is a science. Since it is science by scientific laws in deciding the teaching guidelines and major teaching reform measures must be with scientific attitude and the objective laws of foreign language teaching. To guide college English teaching reform is the theory basis of linguistics is the modern education theory.

College English teaching reform is centered on teaching methods, teaching means and teaching materials from three aspects. (1) Teaching means reform. Students can learning in multimedia center or through campus network anytime and anywhere and be able to download the required material. For this kind of exchange between the students, teachers and students communicate with each other to provide communication platform. In college English teaching in multimedia modern education based on computer and network technology is the inevitable outcome of the development of college English teaching is also the objective requirement of the rapid development of higher 
education in China. (2) Teaching materials reform. Teaching materials should be practical, communicative and interest at an organic whole, emphasis on the basic knowledge of general English language, and combining practice application, learning strategy and cross-cultural communication and practical skills. (3) The teaching method reform. Centering on the students in the general core teaching should adopt more inspired discussion-based teaching method and to cultivate the students' communicative competence as the goal of communicative teaching method and pay attention to training students' individualized learning methods and students' ability of autonomous learning.

College English teaching reform, introduce the network multimedia teaching which is a new education teaching mode, take the student as the main body, teacher as the guidance, all kinds of the resources as the auxiliary, students completely into the teaching activities, teachers use multimedia network for students to create the more real and natural language environment. Correct positioning of the teachers' role, can make the learners in the network multimedia environment more positive and active learning, student-centered teaching method that is better than the traditional teacher-centered teaching method can more effectively improve the students' language ability.

\section{Conclusion}

In this paper, we conduct research on college English teaching model optimization under information technology background with the Xi'an university as the empirical analysis example. Up to now, the research achievements of western phonetic consciousness has a systematic and thorough, the use of phonetic consciousness to help students learn the language has become a universal point of view, and compared with the introduction and research of phonetic consciousness in Chinese academic circle is not enough in-depth, most studies are based on the phonetic consciousness development of preschool children. In our country, college students most of English learners of Chinese learners of English, so the phonetic consciousness of enlightenment for Chinese college students' English learning in the academia is still a need to continue in-depth discussion topic. Therefore, we combine the general core condition of Xi'an university to propose the English teaching model optimization methodology under information technology background that will be meaningful.

\section{Acknowledgement}

This research is financially supported by the key project of ministry of the education of education management information center in 2014. The project title is: Research on the information technology and subject teaching depth fusion under the MOOCs perspective.

\section{Reference}

[1] Alsagoff, Lubna, et al., eds. Principles and practices for teaching English as an international language. Routledge, 2012.

[2] Matsuda, Aya, ed. Principles and practices of teaching English as an international language. Vol. 25. Multilingual Matters, 2012.

[3] Lammers, Jayne C., Jen Scott Curwood, and Alecia Marie Magnifico. "Toward an affinity space methodology: Considerations for literacy research." English Teaching 11.2 (2012): 44.

[4] Qinghua, Li, and Kong Wen. "A validation framework for formative assessment in EFL teaching." Foreign Language Learning Theory and Practice 1 (2015): 005.

[5] Hong, M. A., and L. I. N. Jianqiang. "How Chinese Exchange Students Adapt to Their Academic Course Learningin a US University: A Fresh Look at College English 
Teaching in China." Cross-Cultural Communication 9.3 (2013): 67.

[6] Zainal, Zaidah, Reza Raissi, and Faizah Mohamad Nor. "A comparison between students' and teachers' ideas regarding communicative language teaching implementation in Malaysian secondary schools: A qualitative survey." Journal of Basic and Applied Scientific Research 3.4 (2013): 604-618.
[7] Zhi, Li. "The university English teaching model of independent college [J]." Journal of Jiamusi Education Institute 10 (2013): 230.

[8] Chen, Jing, and Ying Wang. "A study of cooperative learning in higher college English teaching." Theory and Practice in Language Studies 3.7 (2013): 1258. 